\title{
Endoscopic technique for closure of a large gastric tube perforation by using endoclips with line-assisted complete closure
}

Endoscopic submucosal dissection (ESD) is an acceptable treatment for gastric tube cancer after an esophagectomy [1]. However, treatment of lesions on the suture line is difficult and may cause perforations. It is sometimes difficult to

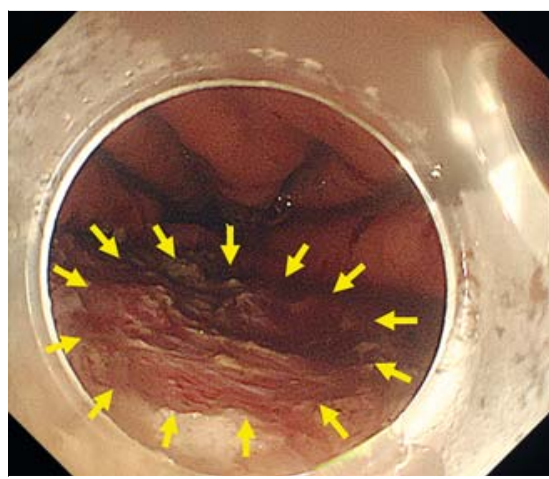

- Fig. 1 Endoscopic view showing a large perforation (yellow arrowheads) in the gastric tube during endoscopic submucosal dissection. close a large perforation with endoclips. We report an endoscopic technique that enabled the closure of a large perforation by using the line-assisted complete closure (LACC) method [2-5].

An 87-year-old man with early gastric cancer located on the suture line of the lesser curvature of the gastric tube, after subtotal esophagectomy, underwent ESD. During ESD, severe fibrosis and staples were encountered in the submucosal layer of the suture line. To achieve en bloc resection, dissection was performed just below the staples. As a result, a large perforation occurred, exposing the mediastinum ( $\triangleright$ Fig. $\mathbf{1}$ ). The perforation could not be closed with endoscopic clip placement because of its large size. Therefore, we endoscopically closed the perforation by using endoclips with LACC ( Fig. 2, $>$ Video 1).

An endoclip (HX-610-090; Olympus, Tokyo, Japan) with 1-0 silk line was placed at the side of the perforation site ( Fig.2a, Fig.3a,b). To anchor the line, another endoclip was placed on the other side ( $\mathbf{F i g . 2} \mathbf{b}$ ). The same procedure was repeated, and a total of four endoclips were placed along the perforation line ( $\triangleright$ Fig. $\mathbf{2 c , d}$, $\mathbf{F i g . 3 c}$ ). Both sides of the perforation were gathered by pulling the anchor line ( $\vee$ Fig. $2 \mathrm{e}$ ). Additional endoclips were placed to achieve complete closure ( $\vee$ Fig. $\mathbf{2 f}$, $\triangleright$ Fig. $\mathbf{3 d}$ ).

After 7 days, an endoscopic examination revealed that the perforation site was filled with regenerating tissue. Therefore, we initiated oral intake, which the patient tolerated well. After 2 months, post-ESD ulcer scarring was observed.

This technique of using endoclips with LACC could be performed relatively easily and is potentially useful in closing a large perforation in the gastrointestinal tract.

Endoscopy_UCTN_Code_CPL_1AH_2AZ

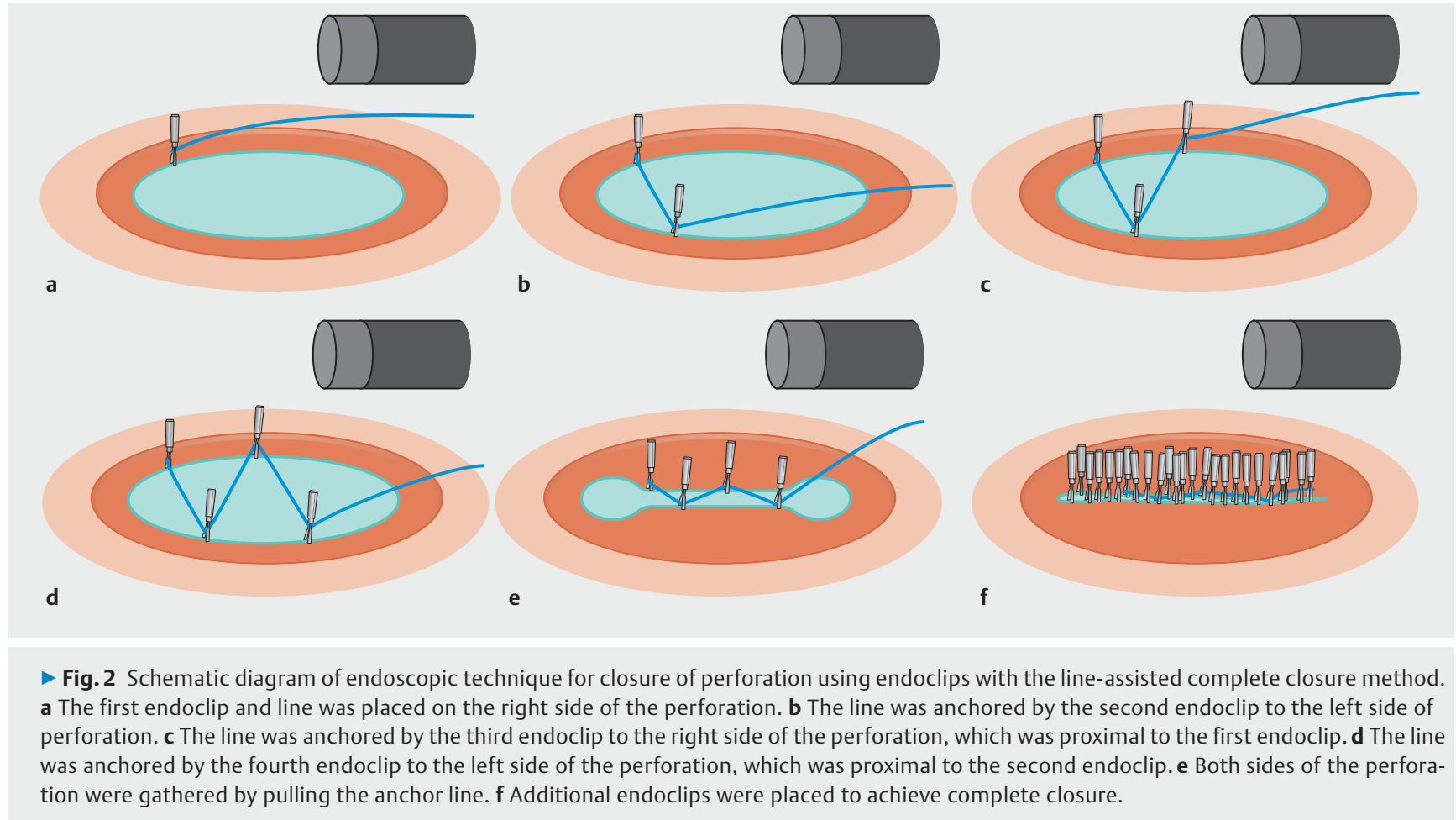




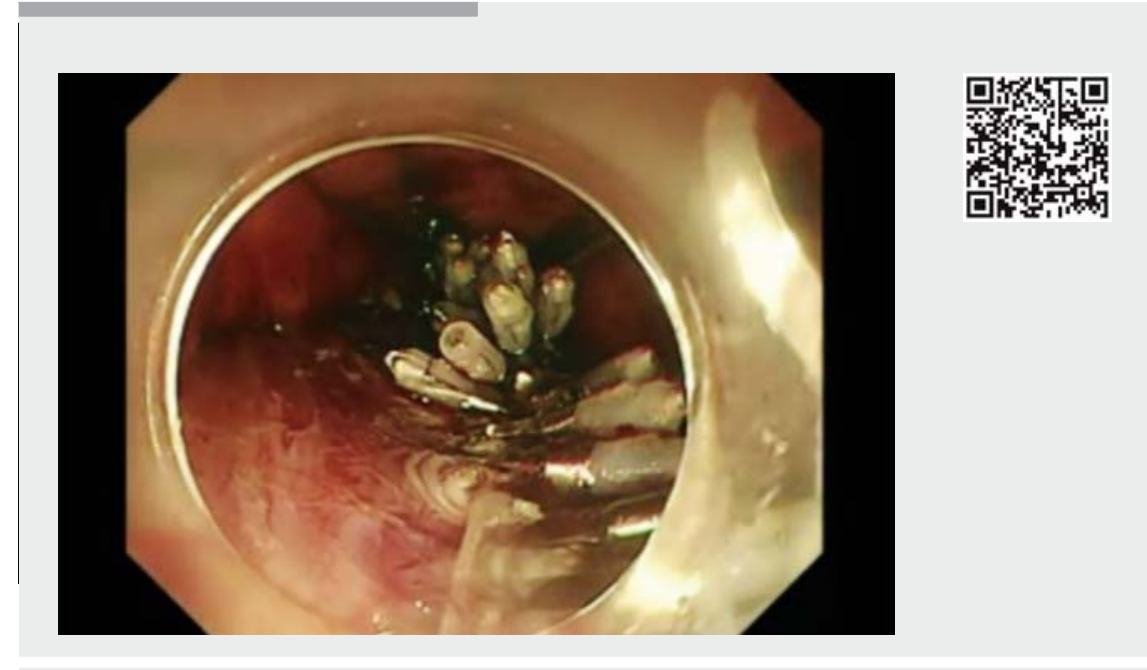

Video 1 Endoscopic technique for closure of a large gastric tube perforation by using endoclips with line-assisted complete closure.
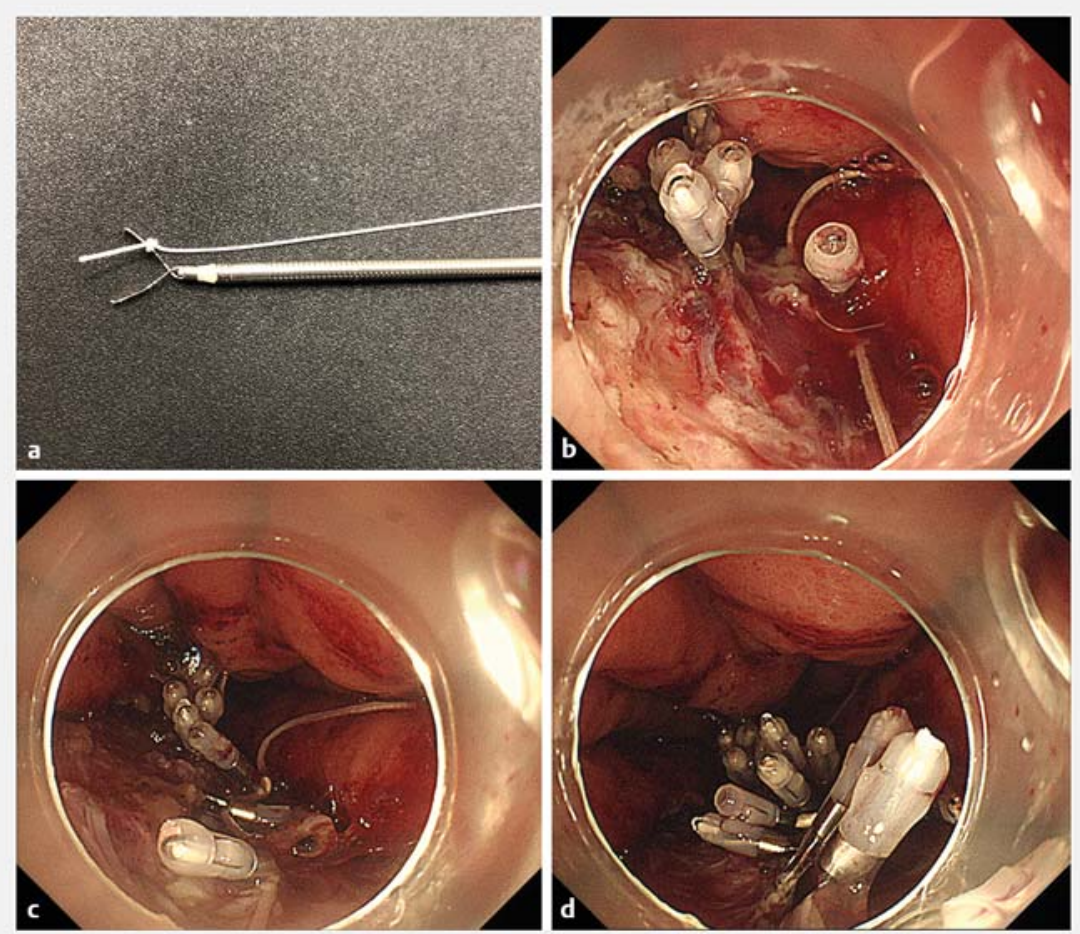

- Fig. 3 Endoscopic technique for closure of perforation using endoclips with the line-assisted complete closure method. a A long silk line was tied to the arm of an endoclip. b The endoclip and line were placed on the side of the perforation. $c$ The line was anchored alternately left and right by using additional endoclips, and both sides of the perforation were gathered by pulling the anchor line. $\mathbf{d}$ Additional endoclips were placed to achieve complete closure.
Competing interests

None

The authors

Masaki Ominami, Yasuaki Nagami, Chieko Tanaka, Taishi Sakai, Shusei Fukunaga, Toshio Watanabe, Yasuhiro Fujiwara

Department of Gastroenterology, Osaka City University Graduate School of Medicine, Osaka, Japan

\section{Corresponding author}

\section{Yasuaki Nagami, MD}

Department of Gastroenterology, Osaka City University Graduate School of Medicine,

1-4-3, Asahimachi, Abeno-ku, Osaka,

545-8585, Japan

Fax: +81-6-66453813

yasuaki1975@hotmail.com

\section{References}

[1] Nonaka S, Oda I, Sato C et al. Endoscopic submucosal dissection for gastric tube cancer after esophagectomy. Gastrointest Endosc 2014; 79: $260-270$

[2] Yahagi N, Nishizawa T, Akimoto T et al. New endoscopic suturing method: string clip suturing method. Gastrointest Endosc 2016; 84: $1064-1065$

[3] Kato M, Takeuchi Y, Yamasaki Y. Line-assisted complete closure of a large colorectal mucosal defect after endoscopic submucosal dissection. Dig Endosc 2016; 28: 686

[4] Kato M, Takeuchi Y, Yamasaki Y et al. Technical feasibility of line-assisted complete closure technique for large mucosal defects after colorectal endoscopic submucosal dissection. Endosc Int Open 2017; 5: E11 -E16

[5] Nakahira H, Takeuchi Y, Garcia JS et al. Lineassisted endoscopic complete closure of a large perforation during colonic endoscopic submucosal dissection. Endoscopy 2018; 50: E32-E33

\section{Bibliography}

DOI https://doi.org/10.1055/a-0800-8502

Published online: 14.12 .2018

Endoscopy 2019; 51: E49-E50

(c) Georg Thieme Verlag KG

Stuttgart $\cdot$ New York

ISSN 0013-726X 